\title{
X-linked Inheritance in Females with Chronic Granulomatous Disease
}

\author{
Elaine L. Mills, Kenneth S. Rholl, and Paul G. Quie, Department of Pediatrics, \\ School of Medicine, University of Minnesota, Minneapolis, Minnesota 55455
}

\begin{abstract}
A B S T RACT Chronic granulomatous disease in males is familial and its transmission is usually clearly $\mathrm{x}$-linked. The mode of inheritance in females with the syndrome is unknown and the carrier state difficult to identify. Defective polymorphonuclear leukocyte bactericidal activity in this disease is associated with an absence of the respiratory burst generated in stimulated phagocytes and may be detected by the chemiluminescence assay. Polymorphonuclear leukocytes from three of four females with chronic granulomatous disease had extremely low chemiluminescence production, their asymptomatic mothers had intermediate values, and their fathers were normal. Polymorphonuclear neutrophils of two affected males in these kinships generated no chemiluminescence, whereas two of seven female relatives had intermediate values, and all nonaffected males had normal values. In the three families in which leukocytes were studied by nitroblue tetrazolium reduction, two populations of neutrophils were demonstrated for the female patients and/or their mothers. The wide phenotypic variability for clinical disease, evidence of two leukocyte populations in the patients or their mothers, and low but detectable leukocyte chemiluminescence in the affected females is consistent with the Lyon hypothesis of $x$-chromosome inactivation in these families. The findings suggest an $x$-linked inheritance in these females with chronic granulomatous disease.
\end{abstract}

\section{INTRODUCTION}

The syndrome of chronic granulomatous disease of childhood is characterized by severe recurrent infections of the skin, subcutaneous tissues, and reticuloendothelial system $(1,2)$. The functional defect has been identified as a severe impairment in polymorpho-

This work was presented in part at the Annual Meeting of the Association of American Physicians, 5-7 May 1978, Washington, D. C.

Address reprint requests to Dr. Mills.

Received for publication 11 February 1980 and in revised form 18 April 1980. nuclear leukocyte intracellular microbial killing $(3,4)$. Polymorphonuclear leukocytes in these patients phagocytize bacteria normally but fail to generate the normal respiratory burst associated with phagocytosis of opsonized particles $(5,6)$ or stimulation by soluble nonparticulate agents (7). Activation of the respiratory burst in normal polymorphonuclear leukocytes is associated with increased oxygen consumption and generation of oxidative intermediates including superoxide anion $(8-10)$, hydrogen peroxide $(11)$, the hydroxyl radical $(12,13)$, and singlet oxygen $(14,15)$. Oxidative intermediates are essential for normal microbicidal activity (4). The depressed intracellular killing of polymorphonuclear leukocytes in chronic granulomatous disease has been attributed to the absence of these intermediates.

Respiratory burst activity in normal polymorphonuclear leukocytes is associated with generation of light energy as chemiluminescence (16-18). This light production is dependent on oxidative intermediates and chemiluminescence can be used as a measure of oxidative metabolism (19-21). The sensitivity of the chemiluminescence assay for detecting oxidative intermediates has been greatly increased by using the cyclic hydrazide, luminol, which reacts as a substrate with these intermediates $(22,23)$. Stimulated polymorphonuclear leukocytes of patients with chronic granulomatous disease fail to generate oxidative intermediates or produce chemiluminescence (24).

Genetic transmission in the majority of chronic granulomatous diseased males has been established as $x$-linked recessive inheritance (25). In family studies, the asymptomatic mothers can be identified as heterozygous carriers by intermediate in vitro leukocyte function, the fathers are normal, and some female relatives can be identified as carriers. The male to female ratio in this disease of seven to one (2) also suggests $x$-linked transmission. On the other hand, chronic granulomatous disease in females (26-35) and in some boys without demonstrable leukocyte defects in either parent (36-38) has suggested another mode of inheritance. 
We report here luminol-amplified polymorphonuclear leukocyte chemiluminescence and histochemical nitroblue tetrazolium (NBT) ${ }^{1}$ studies in four females with chronic granulomatous disease and their families. The findings support an $\mathrm{x}$-linked transmission in all four families.

\section{METHODS}

Patients. Four families, each with one female and a total of two males with chronic granulomatous disease, were studied. These four females represented the total number of females with chronic granulomatous disease in our patient population; none were excluded. The diagnosis of chronic granulomatous disease in both male and female patients has been previously established on the basis of clinical history, markedly reduced polymorphonuclear leukocyte killing of Staphylococcus aureus 502A performed by the method of Quie et al. (3) and failure to reduce NBT dye according to the method of Baehner and Nathan (26) as modified by Windhorst et al. (25).

The polymorphonuclear leukocyte defects of the female patient from family 4 have been previously reported in detail and include significantly diminished oxygen consumption, oxidation of $1-\left[{ }^{14} \mathrm{C}\right]$ glucose during phagocytosis of latex particles (27) and leukocyte glutathione peroxidase activity as compared with the activity of control cells (39).

Family 1. A 15-yr-old white girl was well until $3 \mathrm{yr}$ of age when she developed extensive pulmonary infiltrates with metastatic skin lesions (40). Hyphae of Aspergillus were identified in both the skin and lung biopsies and Aspergillus fumigatus was cultured from the lung biopsy material. The lesions in the lungs and skin cleared on aerosol nystatin therapy. Biopsy-proven pulmonary aspergillosis recurred at 4 and $10 \mathrm{yr}$ of age. She had three additional episodes of clinically similar but unbiopsied pulmonary diseases that were assumed to be due to recurrent aspergillosis. One of these episodes was associated with granulomata of the skin which showed histologic evidence of hyphae. One male sibling and all other family members are healthy. The patient and her mother are products of nonconsanguineous marriages. The pedigree chart (Fig. 1) notes the distribution of the leukocyte abnormalities within the family.

Family 2. A 35-yr-old white woman had recurrent staphylococcal skin abscesses since infancy. In addition, sterile abscesses had been noted at the injection site of each childhood immunization. At $15 \mathrm{yr}$ of age she underwent resection of the upper pole of the left kidney for abscess formation complicating chronic pyelonephritis. At age 19, an infected pilonidal sinus was resected. At age 21 , chronic cavitary pulmonary lesions led to removal of the right middle and right lower lobes of the lung. A Pseudomonas species was cultured from biopsy material. The pathology of the lung tissue showed numerous noncaseating granulomatas with many of the macrophages containing distinct, almost glossy, brownish pigment located in the cytoplasm in the vicinity of the nucleus (41). This woman's son, the product of a nonconsanguineous marriage, had staphylococcal pustules noted at birth. At 15 mo of age, after 3 mo of vomiting, he was found to have a mass lesion obstructing the lumen of the gastric antrum. Biopsy showed many areas of granulomata formation with acute central necrosis and heavy eosinophilic in-

${ }^{1}$ Abbreviations used in this paper: DMSO, dimethyl sulfoxide; HBSS, Hanks' balanced salt solution; NBT, nitroblue tetrazolium; PBS, phosphate-buffered saline; PMA, phorbol myristate acetate.
FAMILY 1

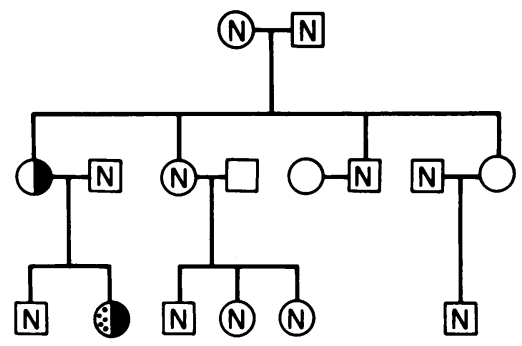

Figure 1 Pedigree of family 1 . The mother and one sister of the female patient (arrow) have intermediate polymorphonuclear leukocyte function as measured by luminol-amplified chemiluminescence and are designated as carriers. (1), normal female, , normal male, $\boldsymbol{O}$, carrier female, $\bullet$, carrier femaleclinical disease, $\mathbf{\square}$, male-clinical disease, $O \square$, not testedclinically well, $\Theta$, spontaneous abortion, + , deceased.

filtrate (42). A sister has had recurrent furuncles since infancy but no visceral organ involvement. A pedigree chart (Fig. 2) notes the distribution of the leukocyte abnormalities within the family.

Family 3. A 26-yr-old white woman has had recurrent pneumonias and skin abscesses. One brother has had recurrent skin abscesses frequently requiring incision and drainage, recurrent pneumonias, and a submandibular abscess. Another brother was first diagnosed at age $16 \mathrm{yr}$ as having ulcerative colitis which was followed by several lung abscesses, a liver and a brain abscess. He died at $24 \mathrm{yr}$ with pulmonary aspergillosis. The other family members are well and the parents are unrelated.

A pedigree chart (Fig. 3) notes the distribution of the leukocyte abnormalities within the family.

Family 4. A 25-yr-old white woman had a history of multiple infections beginning at 8 mo of age. The first $13 \mathrm{yr}$ of her life have been reported in detail (27). Since that time she has had suppurative lymphadenitis, pneumonia, and pyoderma. In addition, she has had two episodes of liver abscesses, one known to be due to Staphylococcus aureus and bilateral tubo-ovarian abscesses due to Serratia marcescens requiring bilateral salpingectomy. Most recently she developed bilateral pneumonitis complicated by gram negative septic shock and disseminated intravascular coagulopathy due to Pseudomonas species. The parents are well and unrelated.

A pedigree chart (Fig. 4) notes the distribution of the leukocyte abnormalities within the family.

\section{FAMILY 2}

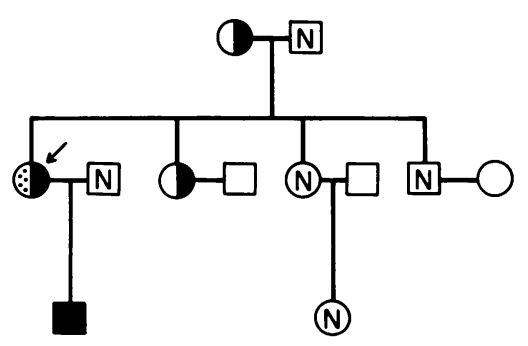

Figure 2 Pedigree of family 2. The mother of the female patient (arrow) has intermediate leukocyte function. Key as for Fig. 1. 
FAMILY 3

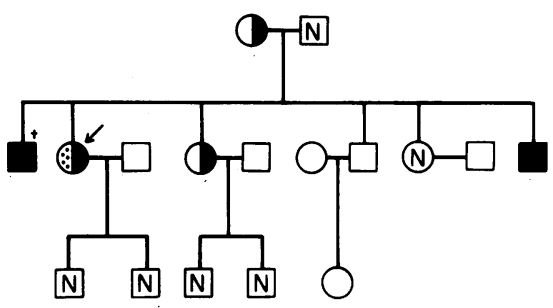

Figure 3 Pedigree of family 3. Legend and key as for Fig. 1.

Preparation of cells. Peripheral blood was drawn by fingerstick into three $65-\mu$ l heparinized minimum $3 \mathrm{U}$. S. Pharmacopeia units ammonium heparin per tube capillary tubes (Dade Div., American Hospital Supply Corp., Miami, Fla.), incubated in $5 \mathrm{ml}$ ice-cold $0.87 \% \mathrm{NH}_{4} \mathrm{Cl}$ for $10 \mathrm{~min}$ at $22^{\circ} \mathrm{C}$. Residual leukocytes were washed twice with Hanks' balanced salt solution (HBSS) pH 7.4 (without phenol red) to which $0.1 \%$ gelatin (wt/vol) was added (gel-Hanks) and the cells resuspended in $1.5 \mathrm{ml}$ gel-Hanks. $75 \mu \mathrm{l}$ of the cell suspension was carefully mixed with an equal volume of counting solution $(0.02 \%$ gentian violet in $3 \%$ acetic acid) and the cells counted on a hemacytometer. Cells were suspended to $2.5 \times 10^{4} / \mathrm{ml}$ gel-Hanks.

Preparation of particles. To prepare the zymosan (Schwarz/Mann Div. Becton, Dickinson \& Co., Orangeburg, N. Y.) suspension, $500 \mathrm{mg}$ of zymosan was suspended in phosphate-buffered saline (PBS), pH 7.4, incubated in a boiling water bath for $1 \mathrm{~h}$, sedimented at $1,000 \mathrm{~g}$ and resuspended in PBS. Zymosan was opsonized by incubating one part zymosan and three parts serum (obtained from three donors) at $37^{\circ} \mathrm{C}$ for $15 \mathrm{~min}$. The suspension was sedimented at $1,000 \mathrm{~g}$ and the zymosan pellet resuspended in PBS to the original four-part volume. Opsonized zymosan suspensions were kept at $4^{\circ} \mathrm{C}$ in the dark until used.

Luminol (5-amino-2,3-dehydro-1,4-phthalazinedione) (Eastman Kodak Co., Rochester, N. Y.) was prepared as a $275-\mu \mathrm{M}$ stock solution in dimethyl sulfoxide, luminol was diluted in PBS ( $\mathrm{pH} 7.4$ ) to a final concentration of $1 \mu \mathrm{M}$ per scintillation vial.

Chemiluminescence assay. The chemiluminescence mixtures were prepared at ambient temperatures in glass scintillation vials by adding $5 \mathrm{mg}$ of opsonized dark-adapted zymosan suspension, $20 \mu \mathrm{l}$ of stock luminol and enough PBS to give a final volume of $5.5 \mathrm{ml}$ (43). The vials were evenly spaced in a beta counting spectrometer, model LS-100C (Beckman Instruments, Fullerton, Calif.), adjusted out of coincidence, and the reaction mixtures allowed to become darkadapted over $20 \mathrm{~min}$. Background counts were obtained. Under red illumination, polymorphonuclear leukocytes were added to each vial at zero time, the phagocytic mixture agitated for $30 \mathrm{~s}$ and each vial counted for $1 \mathrm{~min}$ at ambient temperature. The vials were counted sequentially every 7

\section{FAMILY 4}

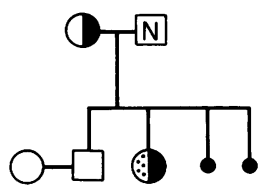

Figure 4 Pedigree of family 4. Legend and key as for Fig. 2. min for a total of $60 \mathrm{~min}$. Background counts obtained from unstimulated granulocytes were subtracted from the values obtained from stimulated cells. Preliminary studies had shown that when light emission was measured continuously with readings obtained every $30 \mathrm{~s}$, chemiluminescence consistently peaked between 8 and $10 \mathrm{~min}$. Therefore, peak activity at $9 \mathrm{~min}$ was compared for statistical analysis. The results, however, were entirely comparable when expressed as an integral value or as peak activity. All assays were performed in duplicate.

Viability of polymorphonuclear leukocytes was $>99 \%$ viable when assessed by trypan blue dye exclusion $(0.1 \%$ trypan blue dye, Gibco Laboratories, Grand Island Biological Co., Grand Island, N. Y.).

The data was tested for statistical significance by use of Student's $t$ test ( $P>0.05$, not significant).

Assay of NBT reduction. All chemicals used were reagent grade. Phorbol myristate acetate (PMA, 12-O-tetradecanoylphorbol-13-acetate, mol wt 616, from Consolidated Midland Corp., Chemical Div., Katonah, N. Y.) was dissolved in dimethyl-sulfoxide (DMSO) at a concentration of $1 \mathrm{mg} / \mathrm{ml}$ and kept frozen at $-70^{\circ} \mathrm{C}$ between experiments. Before use, stock PMA was thawed and diluted in HBSS to $0.1 \mu \mathrm{g} / \mathrm{ml}$. NBT (grade III, Sigma Chemical Co., St. Louis, Mo.) was prepared by dissolving $16.8 \mathrm{mg}$ of NBT powder in $200 \mu \mathrm{l}$ of DMSO at $37^{\circ} \mathrm{C}$, and diluting this in $8.8 \mathrm{ml}$ HBSS. $0.5 \mathrm{ml}$ pooled human serum was added to each $0.9 \mathrm{ml}$ of NBT solution to make the NBT serum solution. The PMA and NBT serum solutions were brought to $37^{\circ} \mathrm{C}$ just before use.

Heparinized venous blood (10 $\mathrm{U}$ heparin $/ \mathrm{ml}$ of blood) was allowed to settle by gravity on lymphocyte separation media (Litton Bionetics, Kensington, Md.) for $40 \mathrm{~min}$ at $22^{\circ} \mathrm{C}$ and the buffy coat removed. $30 \mu \mathrm{l}$ of buffy coat was placed in a polystyrene 1.5-ml conical vial (Bolab Inc., Derry, N. H.) and $100 \mu \mathrm{l}$ of PMA $(1 \mu \mathrm{g} / \mathrm{ml})$ was added. The suspension was incubated in a moist chamber for $10 \mathrm{~min}$ at $37^{\circ} \mathrm{C} .150 \mu \mathrm{l}$ of the cell suspension was placed on a clean glass coverslip and further incubated in a moist chamber for $30 \mathrm{~min}$ at $37^{\circ} \mathrm{C}$ to allow the stimulated cells to adhere to the glass. The coverslips were removed from the chamber and gently washed in sterile normal saline ( $\mathrm{pH} 7.4)$ to remove all nonadherent cells. 100 $\mu l$ of the NBT serum solution was placed in the center of a clean, alcohol flamed glass slide and the coverslips inverted over the NBT serum solution, which was incubated in a moist chamber for $20 \mathrm{~min}$ at $37^{\circ} \mathrm{C}$. The coverslips were carefully removed from the glass slides, washed with normal saline, and air dried at ambient temperature. The coverslips were fixed with absolute methanol for $5 \mathrm{~min}$, rinsed with water, stained with $1 \%$ safranin stain for $5 \mathrm{~min}$, rewashed with water and allowed to air dry. The coverslips were then mounted on clean glass slides and read by two independent observers. 400 cells were counted on each coverslip and classified as NBT positive or NBT negative. Cells were judged NBT negative on the basis of two criteria; (a) their nuclear morphology was intact and they could be identified as neutrophils and; $(b)$ their nuclei stained pink and was not associated with any blue precipitate. Cells were judged NBT positive if they were associated with blue precipitates either in their nuclei or cytoplasm; NBT positive cells could have either intact or distorted nuclei. Controls were unstimulated donor leukocytes incubated in HBSS containing 0.01\% DMSO instead of PMA (PMA was dissolved in $0.01 \%$ DMSO in HBSS). All tests were performed in triplicate.

\section{RESULTS}

Chemiluminescence. Polymorphonuclear leukocyte luminol-amplified chemiluminescent response to 
opsonized zymosan was measured in the families of four females with chronic granulomatous disease. One female patient (family 4$)(27,39)$ was not available for chemiluminescence studies.

Kinetic analysis of the chemiluminescent responses of leukocytes from patients, relatives, and controls showed peak response occurred between 8 and $10 \mathrm{~min}$ after initiation of the reaction. When leukocyte luminescence was monitored every $7 \mathrm{~min}$ as demonstrated for family 1, (Fig. 5), peak values consistently occurred at $9 \mathrm{~min}$. For statistical purposes, peak chemiluminescence values at 9 min were compared for members of all families and their controls (Fig. 6).

The chemiluminescent responses of leukocytes from the three female patients were significantly depressed $\left(11 \pm 4 \times 10^{3} \mathrm{cpm}, \pm 1 \mathrm{SD}\right)$ as compared with normal (control) leukocytes $\left(422 \pm 55 \times 10^{3} \mathrm{cpm}\right)(P<0.001$; Fig. 6) but were similar to their male relatives with the disease $(0 \mathrm{cpm})$. Leukocytes from the mothers of the four female patients produced chemiluminescent responses intermediate $\left(254 \pm 38 \times 10^{3} \mathrm{cpm}\right)$ between patient and control values $(P<0.001$; Fig. 6$)$. The range of values of the chemiluminescent re-

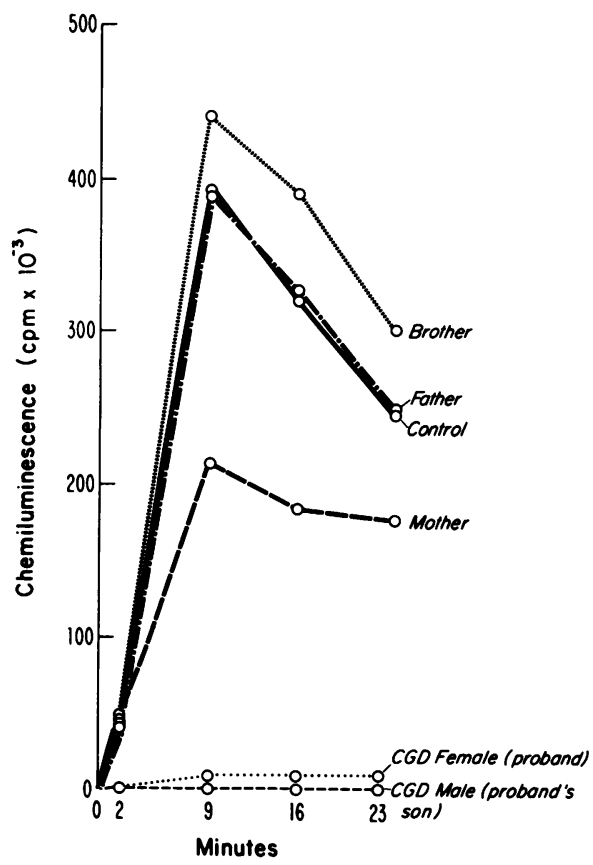

FIGURE 5 Chemiluminescent response of polymorphonuclear leukocytes exposed to opsonized bacteria in the presence of $1 \mu \mathrm{M}$ luminol. The female patients' cells generated a poor chemiluminescent response to zymosan, the patients' mother had a response intermediate between the patient and normal (control) cell responses. Cells from the patients' son had no chemiluminescent response, whereas the patients' brother and father had responses similar to those of normal control cells. CGD, chronic granulomatous disease.

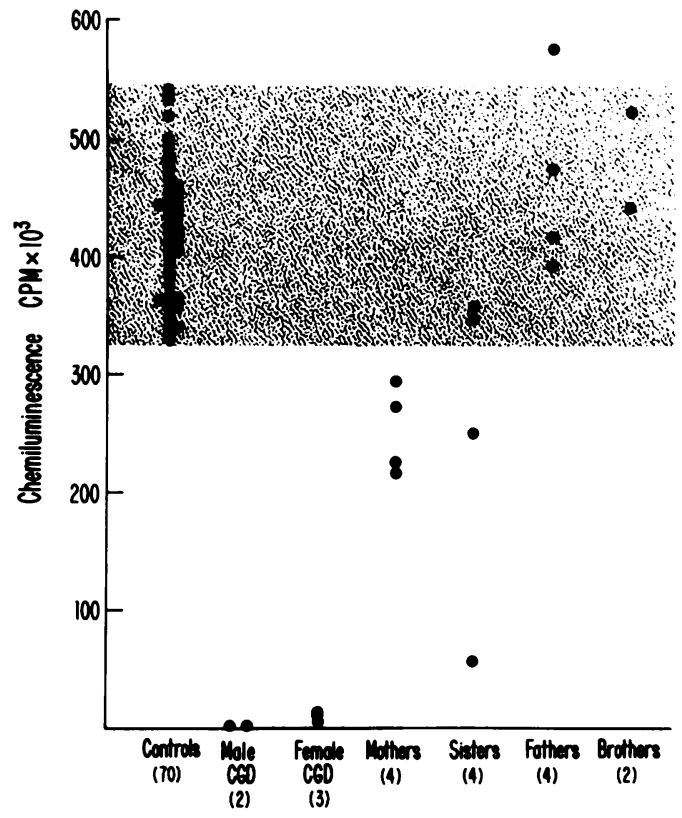

FIGURE 6 The mean peak chemiluminescent response of polymorphonuclear leukocytes phagocytizing opsonized zymosan in the presence of $1 \mu \mathrm{M}$ luminol. The stippled area represents the range of responses from 70 different normal donors. The number of individuals studied are shown in brackets. Cells from the male chronic granulomatous disease patients produced no chemiluminescent response and those from the female patients, very little response. The responses of cells from all of the mothers and two sisters were significantly less than those of 70 normal donors (controls), $P$ $<0.001$. Cells from the fathers, brothers, and two sisters were all within the range of the normal donors.

sponses of the mothers' leukocytes (216-298 $\times 10^{3}$ cpm) was below the range of values for 70 different controls $\left(325-565 \times 10^{3} \mathrm{cpm}\right)$. The chemiluminescent responses of leukocytes from the patients' fathers $\left(451 \pm 81 \times 10^{3} \mathrm{cpm}\right)$ and two brothers $\left(528 \times 10^{3}\right.$, and $442 \times 10^{3} \mathrm{cpm}$ ) were within $2 \mathrm{SD}$ of control values, whereas those from the patients' sisters varied from relatively low values $\left(56 \times 10^{3} \mathrm{cpm}\right)$ to normal values (Fig. 6). All assays were performed in duplicate. The patients and their parents were assayed on at least two different occasions and the values shown are a mean of these assays.

NBT reduction. According to the Lyon hypothesis (44), there should be two distinct populations of polymorphonuclear neutrophils and no hybrid cells in the neutrophil population of a female who is heterozygous for an $\mathrm{x}$-linked recessive gene phenotypically expressed in neutrophil function (44). To determine whether the Lyon hypothesis was operative in our population of female patients, the peripheral blood leukocytes of three females with chronic granulomatous disease and their mothers were examined histochemically by NBT reduction. Under the experimental conditions 

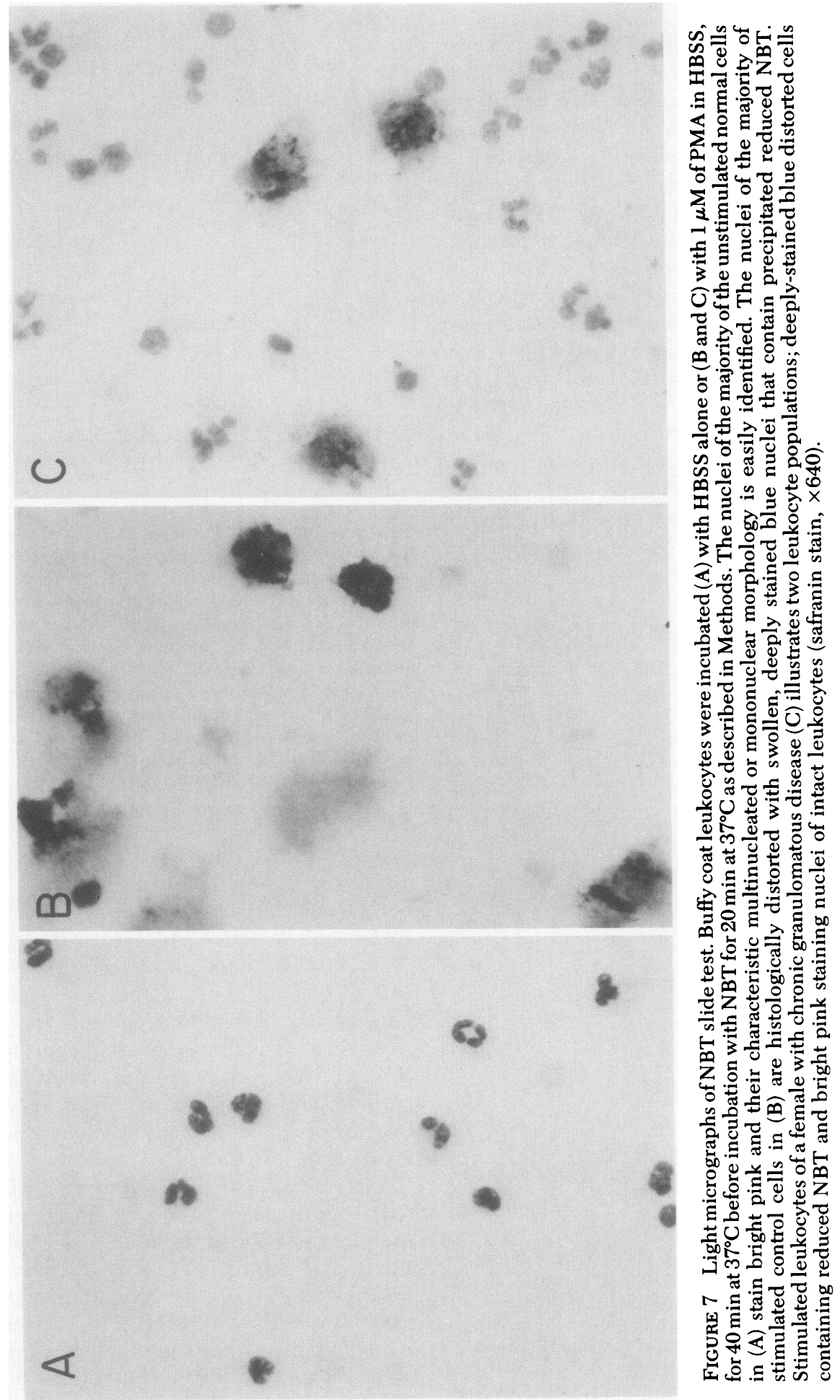
used, the NBT positive leukocytes containing blue formazan precipitates could readily be distinguished from the intact NBT negative cells with the pinkstained multilobulated nuclei. Unstimulated polymorphonuclear leukocytes (Fig. 7[A]) are characterized by distinct nuclear morphology which stains bright pink, and nuclei and cytoplasm that are free of any blue formazan precipitates. Of the $\mathbf{4 0 0}$ leukocytes counted per coverslip of the unstimulated leukocyte preparations, $<2 \%$ of the cells were found to be associated with blue formazan precipitates; these cells were considered to be spontaneously NBT positive. Stimulated normal (donor) leukocytes (Fig. 7[B]) were characteristically swollen, distorted cells with deep staining, fine to coarse precipitates associated with the nuclei and/or the cytoplasm. These NBT positive cells were generally too distorted to be morphologically identifiable as to cell type and the distortion was attributed to the presence of reduced NBT because control preparations of PMA-stimulated leukocytes without NBT were morphologically intact. Since peripheral blood monocytes (45-57), eosinophils (48, 49), and basophils (50), but not lymphocytes (16), all respond to appropriate stimuli with activation of the respiratory burst, these three cell types must all be included as possible NBT positive leukocytes. In contrast, PMA-stimulated leukocytes from a female patient (Fig. 7[C]) were a mixed population of NBT positive and NBT negative leukocytes. The NBT negative leukocytes retained the morphology of intact, unstimulated cells while the NBT positive cells were indistinguishable from the NBT positive cells from controls.

Three female patients and two of their mothers were available for NBT studies (Table I). PMA-stimulated leukocytes from controls were $99 \%$ NBT positive. In family 1 only $10 \%$ of the patients' leukocytes were NBT positive. In family 2 and family 3 the patients had $<1 \%$ NBT positive cells and were comparable to a male patient with chronic granulomatous disease. The mothers of two of the female patients with chronic granulomatous disease had more NBT positive cells than the mother of a male with chronic granulomatous disease.

\section{DISCUSSION}

Genetic transmission in most females with chronic granulomatous disease has been difficult to identify because polymorphonuclear leukocyte defects could not be demonstrated in either parent. In the few exceptions, leukocyte abnormalities were found in the mother but not the father. In one family, polymorphonuclear leukocytes from both the mother and a brother had intermediate responses for NBT reduction (51) whereas in one other family (52) only the mothers' leukocytes produced intermediate responses in NBT
TABLE I

NBT Reduction by Neutrophils Activated with PMA

NBT positive neutrophils

Source of leukocytes

(400 cells counted)

Control

394

Family 1

CGD Female $\quad 0$

Mother

320

Family 2

CGD Female 23

Mother

ND

Family 3

CGD Female $\quad 0$

Mother 364

CGD Male

364
0

Mother of CGD Male

281

ND, not done. CGD, chronic granulomatous disease.

reduction, bactericidal activity, and cytochrome $\mathrm{C}$ reduction. In both families, the father had normal leukocyte function. The inability to detect the carrier state in families of females with chronic granulomatous disease has suggested a non-x-linked mode of transmission in these individuals.

The use of insufficiently sensitive assays to measure leukocyte function may in part be responsible for the inability to detect polymorphonuclear leukocytic defects in mothers of either male or female chronic granulomatous disease patients. Polymorphonuclear leukocyte bactericidal activity in asymptomatic mothers of males with the disease has shown a wide spectrum of activity ranging from normal to levels comparable with that of the patients themselves $(38,43)$. NBT reduction, a respiratory-burst-dependent chemical reaction between the dye and the $\mathrm{O}_{2}^{-}$generated during the respiratory burst (53), has also been used as a measure of polymorphonuclear leukocyte oxidative function. This assay, however, is also of limited value in predicting the chronic granulomatous disease heterozygous state. Normal NBT reduction has been observed in four of five mothers of male patients from families in which a clear-cut pattern of $x$-linked inheritance could be demonstrated (38).

The luminol-dependent chemiluminescence assay used in this study was designed to detect subtle abnormalities in polymorphonuclear leukocyte oxygen metabolism. In this system, respiratory burst activity is maximally stimulated by using an excessive number of ingestable particles. The oxygen intermediates generated during the respiratory burst oxidize available substrates. The zymosan particles employed are themselves oxidizable species but the magnitude of light generated can be greatly augmented by introducing luminol, another oxidizable agent, into the system. When luminol, a cyclic hydrazide, reacts with any of a 
variety of oxidizing agents, the electronically excited aminophthalate ion is generated and relaxes to ground state by photon emission (54). Although light emission by stimulated polymorphonuclear leukocytes remains a nonspecific manifestation of the respiratory burst, and the mechanism of luminol-amplification is not fully understood, this assay has nevertheless proven to be an extremely useful and sensitive measure of neutrophil function $(22,23,43)$.

In the present study, respiratory burst activity was measured by polymorphonuclear leukocyte chemiluminescent response during phagocytosis of zymosan particles. Leukocytes from the two male patients had no chemiluminescent response, cells from the three female patients had extremely low leukocyte responses, and those from the mothers had values intermediate between the patients and controls.

The complete absence of respiratory burst activity in leukocytes from the two male patients reported here and five males previously reported (43) is consistent with the hemizygous state of a defective gene. Homozygosity in females for the same gene which specifies the disease in males, would also be expected to result in the complete absence of leukocyte chemiluminescence. The low but detectable light production in the leukocytes from female patients is more suggestive of a mixed population of normal and abnormal cells such as that found in heterozygous females. There is little evidence for homozygosity in these kindreds. Homozygosity on the basis of autosomal recessive inheritance seems unlikely because intermediate leukocyte function has been demonstrated in each of the four mothers and all the fathers have normal leukocyte function. Homozygosity due to spontaneous mutation in the germ line of the father, or postzygotic somatic mutation in the female herself, however, cannot be ruled out. Genetic abnormalities such as Turner's syndrome or testicular feminization is ruled out in the two females who have borne children. The sex of the third female was confirmed by buccal smear (39).

The Lyon hypothesis could best explain how the occasional heterozygous females, such as the four reported here, have the clinical syndrome of chronic granulomatous disease. By the Lyon hypothesis, there is random and permanent inactivation of one $x$-chromosome in somatic cells early in fetal development. The pattern of inactivation is inherited by all daughter cells (44). This should result in two distinct populations of polymorphonuclear leukocytes but no hybrid cells. Supporting this postulate, two populations of polymorphonuclear leukocytes have been identified in the peripheral blood of heterozygous females by NBT reduction (25) and by autoradiographic studies of bacteria iodination (55). Two populations of polymorphonuclear leukocytes were also identified by NBT reduction in our female patients. Random inactivation of the $\mathrm{x}$-chromosome would be expected to lead to an even distribution of normal and defective cells in heterozygous individuals. However, by chance, the distribution could vary, resulting in a few individuals with preferential inactivation of the defective $x$ chromosome and phenotypically near normal polymorphonuclear leukocyte function. This mechanism could explain the findings of normal leukocyte function in some mothers of either male and female patients. By the same process of random $x$-chromosome inactivation, a few individuals with preferential inactivation of the normal $x$-chromosome would be expected to have markedly abnormal polymorphonuclear neutrophils in which defective respiratory burst activity would be associated with decreased bactericidal activity and clinical disease.

There is evidence from other $x$-linked diseases, i.e., glucose-6-phosphate dehydrogenase deficiency and hemophilia for nonrandom inactivation of the $x$ chromosome and clinical disease in heterozygous females (56). The wide variation in clonal population of neutrophils in heterozygotes may possibly be due to selection similar to the situation in Lesch-Nyhan syndrome, another disease with $\mathrm{x}$-linked inheritance. No environmental or genetic factors that influence the proportion of neutrophils that respond to stimulation by NBT reduction has been identified in carrier females. Further evidence against selection is the relatively constant percentage of NBT positive and NBT negative neutrophils in carrier females over time (unpublished observations).

The findings presented here support an $x$-linked inheritance in females with chronic granulomatous disease and are consistent with the Lyon hypothesis of $x$-chromosome inactivation. The criteria for $x$-linked transmission have been met in the four kindreds. The mothers of the affected females have intermediate polymorphonuclear leukocyte function, the fathers and all male relatives without disease have normal function, whereas the maternal history is positive for affected males and heterozygous females. There is no male to male transmission. The Lyon hypothesis explains the variability of expression in the heterozygous females. Thus, females heterozygous for chronic granulomatous disease may have near normal, intermediate, or severely abnormal polymorphonuclear leukocyte function. Depending upon the degree of their leukocyte dysfunction, they may be phenotypically normal individuals, or express mild to severe forms of the clinical syndrome.

The findings of $x$-linked transmission in both males and females with chronic granulomatous disease does not imply a single gene defect in these individuals. Chronic granulomatous disease may represent a heterogenous collection of leukocyte respiratory-burst ab- 
normalities which are transmitted by genes on the $\mathrm{x}$-chromosome.

\section{ACKNOWLEDGMENTS}

We wish to acknowledge the helpful discussions with Dr. Robert Gorlin and Dr. Richard King.

This work was supported by grants AI-06931-13 and AI08821-10 from the National Institutes of Allergy and Infectious Diseases, and in part by the Minnesota Medical Foundation. Dr. Mills was a fellow of the Minnesota Heart Association during part of these studies.

\section{REFERENCES}

1. Berendes, H., R. A. Bridges, and R. A. Good. 1957. A fatal granulomatosis of childhood: the clinical study of a new syndrome. Minn. Med. 40: 309-312.

2. Johnston, R. B., Jr., and S. L. Newman. 1977. Chronic granulomatous disease. Pediatr. Clin. N. Am. 24: 365-376.

3. Quie, P. G., J. G. White, B. Holmes, and R. A. Good. 1967. In vitro bactericidal capacity of human polymorphonuclear leukocytes. Diminished activity in chronic granulomatous disease of childhood. J. Clin. Invest. 46: 668-679.

4. Babior, B. M. 1978. Oxygen-dependent microbial killing by phagocytes. N. Engl.J. Med. 298: 659-668; 721-725.

5. Holmes, B., A. R. Page, and R. A. Good. 1967. Studies of the metabolic activity of leukocytes from patients with a genetic abnormality of phagocytic function.J. Clin. Invest. 46: 1422-1432.

6. Curnutte, J. T., D. M. Whitten, and B. M. Babior. 1974. Defective superoxide production by granulocytes from patients with chronic granulomatous disease. N. Engl. J. Med. 290: 593-597.

7. Harvath, L., and B. R. Anderson. 1979. Defective initiation of oxidative metabolism in polymorphonuclear leukocytes. N. Engl. J. Med. 300: 1130-1135.

8. Babior, B. M., R. S. Kipnes, and J. T. Curnutte. 1973. Biological defense mechanisms. The production by leukocytes of superoxide, a potential bactericidal agent. J. Clin. Invest. 52: 741-744.

9. Curnutte, J. T., and B. M. Babior. 1974. Biological defense mechanisms. The effects of bacteria and serum on superoxide production by granulocytes. J. Clin. Invest. 53: $1662-1672$.

10. Klebanoff, S. J. 1974. Role of the superoxide anion in the myeloperoxidase-mediated antimicrobial system. J. Biol. Chem. 249: 3724-3728.

11. Root, R. K., J. Metcalf, N. Oshino, and B. Chance. 1975. $\mathrm{H}_{2} \mathrm{O}_{2}$ release from human granulocytes during phagocytosis. I. Documentation, quantitation, and some regulating factors. J. Clin. Invest. 55: 945-955.

12. Tauber, A. I., and B. M. Babior. 1977. Evidence for hydroxyl radical production by human neutrophils. $J$. Clin. Invest. 60: 374-379.

13. Weiss, S. J., P. K. Rustagi, and A. F. LoBuglio. 1978. Human granulocyte generation of hydroxyl radical. $J$. Exp. Med. 147: 316-323.

14. Allen, R. C., R. L. Stjernholm, and R. H. Steele. 1972. Evidence for the generation of an electronic excitation state(s) in human polymorphonuclear leukocytes and its participation in bactericidal activity. Biochem. Biophys. Res. Commun. 47: 679-684.

15. Krinsky, N. I. 1974. Singlet excited oxygen as a mediator of the antibacterial action of leukocytes. Science (Wash. D. C.). 186: 363-365.
16. Rosen, H., and S. J. Klebanoff. 1979. Bactericidal activity of a superoxide anion-generating system. J. Exp. Med. 149: $27-39$.

17. Allen, R. C. 1973. Studies on the generation of electronic excitation states in human polymorphonuclear leukocytes and their participation in microbial activity. Dissertation. Tulane University, New Orleans.

18. Cheson, B. D., R. L. Christensen, R. Sperling, B. E. Kohler and B. M. Babior. 1976. The origin of the chemiluminescence of phagocytosing granulocytes. J. Clin. Invest. 58: 789-796.

19. Allen, R. C., R. L. Stjernholm, M. A. Reed, T. B. Harper, S. Gupta, R. H. Steele, and W. W. Waring. 1977. Correlation of metabolic and chemiluminescent responses of granulocytes from three female siblings with chronic granulomatous disease. J. Infect. Dis. 136: 510-518.

20. Rosen, H., and S. J. Klebanoff. 1976. Chemiluminescence and superoxide production by myeloperoxidase-deficient leukocytes. J. Clin. Invest. 58: 50-60.

21. Harvath, L., H. J. Amirault, and B. R. Andersen. 1978. Chemiluminescence of human and canine polymorphonuclear leukocytes in the absence of phagocytosis. $J$. Clin. Invest. 61: 1145-1154.

22. Allen, R. C., and L. D. Loose. 1976. Phagocytic activation of a luminol-dependent chemiluminescence in rabbit alveolar and peritoneal macrophages. Biochem. Biophys. Res. Commun. 69: 245-252.

23. Stevens, P., D. J. Winston, and K. Van Dyke. 1978. In vitro evaluation of opsonic and cellular granulocyte function by luminol-dependent chemiluminescence: utility in patients with severe neutropenia and cellular deficiency states. Infect. Immun. 22: 41-51.

24. Stjernholm, R. L., R. C. Allen, R. H. Steele, W. W. Waring, and J. A. Harris. 1973. Impaired chemiluminescence during phagocytosis of opsonized bacteria. Infect. Immun. 7: 313-314.

25. Windhorst, D. B., A. R. Page, B. Holmes, P. G. Quie, and R. A. Good. 1968. The pattern of genetic transmission of the leukocyte defect in fatal granulomatous disease of childhood. J. Clin. Invest. 47: 1026-1034.

26. Baehner, R. L., and D. G. Nathan. 1968. Quantitative nitroblue tetrazolium test in chronic granulomatous disease. N. Engl. J. Med. 278: 971-976.

27. Quie, P. G., E. L. Kaplan, A. R. Page, F. L. Gruskay, and S. E. Malawista. 1968. Defective polymorphonuclear leukocyte function and chronic granulomatous disease in two female children. N. Engl. J. Med. 289: 976-980.

28. Azimi, P. H., J. G. Bobenbender, R. L. Hintz, and S. B. Kontras. 1968. Chronic granulomatous disease in three female siblings. JAMA (J. Am. Med. Assoc.). 206: 2865-2870.

29. Ochs, H. D., and R. P. Igo. 1973. The NBT slide test: a simple screening method for detecting chronic granulomatous disease and female carriers.J. Pediatr. 83: 77-82.

30. Wilson, H., W. M. Larson, and D. I. Webb. 1974. NBT results in chronic granulomatous disease. J. Pediatr. 84: $311-312$.

31. Biggar, W. D., S. Buron, and B. Holmes. 1976. Chronic granulomatous disease in an adult male: a proposed $\mathrm{x}$ linked defect. J. Pediatr. 88: 63-70.

32. Carruthers, J. A., and M. W. Greaves. 1976. Chronic granulomatous disease. Br. J. Derm. (Suppl.) 14: 72-74.

33. McPhail, L. C., L. R. DeChatelet, P. S. Shirley, C. Wilfert, R. B. Johnston Jr., and C. E. McCall. 1977. Deficiency of NADPH oxidase activity in chronic granulomatous disease. J. Pediatr. 90: 213-217.

34. Clark, R. A., and S. J. Klebanoff. 1978. Chronic granulomatous disease. Studies of a family with impaired neutro- 
phil chemotactic, metabolic and bactericidal function. Am. J. Med. 65: 941-948.

35. Segal, A. Q., O. T. G. Jones, D. Webster, and A. C. Allison. 1978. Absence of a newly described cytochrome $b$ from neutrophils of patients with chronic granulomatous disease. Lancet. II: 446-449.

36. Kontras, S. B., and J. C. Bass. 1969. Chronic granulomatous disease. Lancet. II: 646-647.

37. Dupree, E., C. W. Smith, and N. L. Taylor-MacDougall. 1972. Undetected carrier state in chronic granulomatous disease. J. Pediatr. 81: 770-774.

38. Repine, J. E., C. C. Clawson, J. G. White, and B. Holmes. 1975. Spectrum of function of neutrophils from carriers of sex-linked chronic granulomatous disease. J. Pediatr. 87: 901-907.

39. Holmes, B., B. H. Park, S. E. Malawista, P. G. Quie, D. L. Nelson, and R. A. Good. 1970. Chronic granulomatous disease in females: a deficiency of leukocyte glutathione peroxidase. N. Engl. J. Med. 283: 217-221.

40. Veeder, J. S., and W. F. Schorr. 1969. Primary disseminated pulmonary aspergillosis with metastatic skin nodules. JAMA (J. Am. Med. Assoc.). 209: 1191-1195.

41. Landing, B. H., and H. S. Shirley. 1957. A syndrome of recurrent infection and infiltration of vicera by pigmented lipid histiocytes. Pediatrics. 20: 431-438.

42. Griscom, N. T., J. A. Kirkpatrick, Jr., B. R. Girdany, W. E. Berdon, R. J. Grand, and G. G. Mackie. 1974. Gastric antral narrowing in chronic granulomatous disease of childhood. Pediatrics. 54: 456-460.

43. Mills, E. L., K. S. Rholl, and P. G. Quie. 1978. Chemiluminescence: a rapid sensitive method for detection of patients with chronic granulomatous disease (CGD) and identification of carriers. Pediatr. Res. 12: 454. (Abstr.)

44. Lyon, M. F. 1972. X-chromosome inactivation and development patterns in mammals. Biol. Rev. 47: 1-35.

45. Nelson, R. D., E. L. Mills, R. L. Simmons, and P. G. Quie. 1976. The chemiluminescence response of phagocytizing human monocytes. Infect. Immun. 14: 129-134.

46. Johnston, R. B., Jr., J. E. Lehmeyer, and L. A. Guthrie.
1976. Generation of superoxide anion and chemiluminescence by human monocytes during phagocytosis and on contact with surface bound immunoglobulin G. J. Exp. Med. 143: 1551-1556.

47. Sagone, A. L., Jr., G. W. King, and E. N. Metz. 1976. A comparison of the metabolic response of phagocytosis in human granulocytes and monocytes. J. Clin. Invest. 57: 1352-1358.

48. DeChatelet, L. R., P. S. Shirley, L. C. McPhail, C. C. Huntley, H. B. Muss, and D. A. Bass. 1977. Oxidative metabolism of the human eosinophil. Blood. 50: 525-535.

49. Klebanoff, S. J., D. T. Durack, H. Rosen, and R. A. Clark. 1977. Functional studies on human peritoneal eosinophils. Infect. Immun. 17: 167-173.

50. Hendersen, W. R., and M. Kaliner. 1978. Immunologic and nonimmunologic generation of superoxide from mast cells and basophils. J. Clin. Invest. 61: 187-196.

51. Bjorksten, B., and K. M. Lundmark. 1972. Abnormal nitroblue tetrazolium test in relatives of a female with chronic granulomatous disease. Scand. J. Infect. Dis. 4: 167-169.

52. Miyazaki, S., H. Shin, N. Goyz, and A. Nakagawara. 1976. Identification of a carrier mother of a female patient with chronic granulomatous disease. J. Pediatr. 89: 784-786.

53. Baehner, R. L., L. A. Boxer, and J. Davis. 1976. The biochemical basis of nitroblue tetrazolium reduction in normal human and chronic granulomatous disease polymorphonuclear leukocytes. Blood. 48: 309-313.

54. White, E. H., and R. B. Brundrett. 1973. The chemiluminescence of acyl hydrazides. In Chemiluminescence and Bioluminescence. 2nd edition. M. F. Cormier, D. M. Hercules, and J. Ledd, editors. Plenum Publishing Corp. New York. 231-244.

55. Klebanoff, S. J., and L. R. White. 1969. Iodination defect in the leukocytes of a patient with chronic granulomatous disease of childhood. N. Engl. J. Med. 280: 460-466.

56. Brock, D. J. H. 1978. The Biochemical Genetics of Man. 2nd edition. D. J. H. Brock and O. Mayo, editors. Academic Press, Inc., London. 511-515. 